OPEN ACCESS

Edited by: József Tímár,

Semmelweis University, Hungary

*Correspondence:

Krisztina Bogos

bogos@koranyi.hu

Zoltan Kiss

zoltan_kiss2@merck.com

${ }^{\dagger}$ These authors have contributed equally to this work

Received: 08 September 2020 Accepted: 24 February 2021 Published: 30 April 2021

Citation:

Bogos K, Kiss Z, Tamási L, Ostoros G, Müller V, Urbán L, Bittner $N$, Sárosi $V$, Vastag A, Polányi Z, Nagy-Erdei Z, Daniel A, Vokó Z, Nagy B, Horváth $K$, Rokszin G, Abonyi-Tóth Z, Barcza Z, Gálffy G and Moldvay J (2021) Improvement in Lung Cancer Survival: 6-Year Trends of Overall Survival at Hungarian Patients Diagnosed in 2011-2016.

Pathol. Oncol. Res. 27:603937. doi: 10.3389/pore.2021.603937

\section{Improvement in Lung Cancer Survival: 6-Year Trends of Overall Survival at Hungarian Patients Diagnosed in 2011-2016}

\author{
Krisztina Bogos ${ }^{1 *}$, Zoltan Kiss ${ }^{2 *}$, Lilla Tamási ${ }^{3}$, Gyula Ostoros ${ }^{1}$, Veronika Müller ${ }^{3}$, \\ László Urbán ${ }^{4}$, Nóra Bittner ${ }^{5}$, Veronika Sárosi ${ }^{6}$, Aladár Vastag ${ }^{2}$, Zoltán Polányi ${ }^{2}$, \\ Zsófia Nagy-Erdei ${ }^{2}$, Andrea Daniel ${ }^{2}$, Zoltán Vokó ${ }^{7}$, Balázs Nagy ${ }^{7}$, Krisztián Horváth $^{7}$, \\ György Rokszin ${ }^{8}$, Zsolt Abonyi-Tóth ${ }^{8,9}$, Zsófia Barcza $^{10}$, Gabriella Gálffy ${ }^{11}$ and \\ Judit Moldvay ${ }^{12,13}$
}

\begin{abstract}
${ }^{1}$ National Korányi Institute of Pulmonology, Budapest, Hungary, ${ }^{2}$ MSD Pharma Hungary Ltd, Budapest, Hungary, ${ }^{3}$ Department of Pulmonology, Semmelweis University, Budapest, Hungary, ${ }^{4}$ Matrahaza Healthcare Center and University Teaching Hospital, Matrahaza, Hungary, ${ }^{5}$ Pulmonology Clinic University of Debrecen, Debrecen, Hungary, ${ }^{6}$ Faculty of Medicine, University of Pécs, Pécs, Hungary, ${ }^{7}$ Eötvös Loránd University, Budapest, Hungary, ${ }^{8}$ RxTarget Ltd. Szolnok, Budapest, Hungary, ${ }^{9}$ University of Veterinary Medicine Budapest, Budapest, Hungary, ${ }^{10}$ Syntesia Ltd, Budapest, Hungary, ${ }^{11}$ Pulmonology Hospital Törökbálint, Budapest, Hungary, ${ }^{12}$ Ist Department of Pulmonology, National Korányi Institute of Pulmonology, Semmelweis University, Budapest, Hungary, ${ }^{13} 2$ nd Department of Pathology, MTA-SE NAP, Brain Metastasis Research Group, Hungarian Academy of Sciences, Semmelweis University, Budapest, Hungary
\end{abstract}

Objective: Lung cancer is one of the most common cancers worldwide and its survival is still poor. The objective of our study was to estimate long-term survival of Hungarian lung cancer patients at first time based on a nationwide review of the National Health Insurance Fund database.

Methods: Our retrospective, longitudinal study included patients aged $\geq 20$ years who were diagnosed with lung cancer (ICD-10 C34) between January 1, 2011 and December 31,2016 . Survival rates were evaluated by year of diagnosis, patient gender and age, and morphology of lung cancer.

Results: 41,854 newly diagnosed lung cancer patients were recorded. Mean age at diagnosis varied between 64.7 and 65.9 years during study period. One- and 5-year overall survival rates for the total population were 42.2 and $17.9 \%$, respectively. Survival was statistically associated with gender, age and type of lung cancer. Female patients $(n=$ 16,362) had 23\% better survival (HR: 0.77, 95\% confidence interval (Cl): 0.75-0.79; $p<$ $0.001)$ than males $(n=25,492)$. The highest survival rates were found in the $20-49$ age cohort $(5 Y=31.3 \%)$ and if the cancer type was adenocarcinoma $(5 Y=20.5 \%)$. We measured $5.3 \%$ improvement $(9.2 \%$ adjusted) in lung cancer survival comparing the period 2015-2016 to 2011-2012 (HR: 0.95 95\% Cl: 0.92-0.97; $p=0.003$ ), the highest at females $<60$ year ( 0.86 (adjusted HR was 0.79 ), interaction analysis was significant for age and histology types.

Conclusion: Our study provided long-term Lung cancer survival data in Hungary for the first time. We found a 5.3\% improvement in 5-year survival in 4 years. Women and young 
patients had better survival. Survival rates were comparable to-and at the higher end of-rates registered in other East-Central European countries (7.7\%-15.7\%).

Keywords: lung cancer, long-term survival, mortality, Hungary, survival

\section{INTRODUCTION}

Lung cancer (LC) is a rapidly progressing, life-threatening disease [1], which constitutes a major disease burden [2,3]. Despite continuous advances in surgical, radio- and systemic treatment procedures (like targeted and immunotherapy) over the past years, lung cancer still has one of the lowest survival rates among carcinomas, making it one of the most important health problems of the 21 st century $[4,5]$.

Variations in cancer survival between countries of comparable affluence and health systems have prompted international efforts to better understand the root of these differences. One-if not the main-reason for poor lung cancer survival may be late diagnosis [6]. Overall, the 5-year lung cancer survival rate is one of the poorest among cancers. The 5-year survival of LC, at all stages combined, varied between 10 and 20\% in Europe in 2010-2014 prior to the modern immune-oncology era [7]. According to the 2019 Fact \& Figures publication of the American Cancer Society, the 5-year survival rate for non-small cell lung cancer (NSCLC) was $23 \%$, compared to $6 \%$ for small-cell lung cancer [8]. Lung cancer survival varies greatly depending on the stage of the disease and the time of diagnosis. According to the seventh edition of the nonsmall cell lung cancer (NSCLC) TNM groupings, 5-year survival estimates in NSLCC ranged from $73 \%$ in stage IA disease to $13 \%$ in stage IV disease [9]. A recently published comprehensive literature review investigating changes in lung cancer survival over a four decade-long period confirmed that female patients had a better long-term (5-year) survival rate (17.7\%) than male patients (13.0\%) [10]. In general, elderly lung cancer patients had poorer survival rates than younger patients. Notably, all age groups have shown a marked increase in survival rates over the decades since the 1970s, particularly in the 15-44 age-group, where 5-year survival exceeded $30 \%$ by 2010 [10].

According to the CONCORD-3 study, LC 5-year survival rates fluctuated between 7.7 and 15.7\% in East-Central Europe within the 2010-2014 period [7]. Though Hungarian lung cancer incidence is among the highest in Europe [11], to date, there is no data regarding the long-term survival of Hungarian lung cancer patients. Therefore, the objective of our nationwide study was to investigate the 5-year survival rates of patients who were newly diagnosed with LC between 2011 and 2016. Our analysis also aimed to examine the effects of age, gender and the tumors' histological characteristics on survival as well as to assess the changes in survival rates during the study period.

\section{MATERIALS AND METHODS}

\section{Study Design}

This nationwide, retrospective study used the claim database of the National Health Insurance Fund of Hungary (NHIF), which is a nationwide insurance system (covering almost $100 \%$ of the Hungarian population), as data source. The NHIF database contains medical information regarding ID and ICD-10 codes of the in- and out-patient visits and procedures involved in medical care, containing $100 \%$ of lung cancer related intervention as there is no other insurance system for Hungarian citizens for lung cancer treatment. The study was approved by the National Ethical Committee, with the 10338-5/ 2019/EKU ethical approval number and the I043/88/2019 study license number.

Lung cancer (ICD-10 C34) patients newly diagnosed between January 1, 2011 and December 31, 2016 and $\geq 20$ years or older at the time of diagnosis were included in our study. In order to identify newly diagnosed LC patients from 2011, we set a reference screening period for 2009-2010. Potential miscoding of lung cancer was prevented by only including patients with a minimum of two records of the C34 ICD-10 code within an interval of over 30 but less than 365 days following the first coding. Patients with only one recorded C34 code who died within 60 days after coding, were also included. If patients had ICD-10 codes related to other cancers or if they were administered oncological treatment other than the lung cancer-specific treatment protocol 6 months prior to or 12 months following the first recorded lung cancer code, then these patients were excluded.

Newly diagnosed LC patients were followed up until December 31, 2016 or alternatively until their dates of death, which were also obtained from the NHIF database. Since the immediate cause of death was not available from this data source, all-cause mortality data were accessed. During data collection, data were anonymized and only non-identifiable data were used in the investigation. The total number of newly diagnosed lung cancer patients per year is shown as crude numbers $(n)$. For the total number of patients and for both genders separately, the mean ages at diagnosis were determined for the 2011-2012, 2013-2014 and for 2015-2016 diagnostic time intervals. As NHIF database could not provide data on cause specific mortality, therefore we calculated and report overall survival of the Hungarian lung cancer patients as defined by Tan et al. [12]. We investigated survival rates in relation to the pathomorphological types of lung cancer in the patient population, where data were available. Stage of disease was not recorded in the NHIF database. We drew Kaplan-Meier curves to show overall survival. Cox regression model was used estimate the association between gender, age and survival. Interaction between age and gender was also studied. Cox regression was also used to calculate the hazard ratio of death of patients diagnosed between 2015 and 2016 vs. between 2011 and 2012 with adjustment for age. Sex, histology type of lung cancer and main first line treatment type. Interaction between age and period of diagnosis was also studied. All calculations were 
TABLE 1 | Patient characteristics.

\begin{tabular}{|c|c|c|c|c|c|c|c|c|}
\hline \multirow[b]{2}{*}{ Patients with new LC diagnosis $(n)$} & \multicolumn{2}{|c|}{ 2011-2012 } & \multicolumn{2}{|c|}{ 2013-2014 } & \multicolumn{2}{|c|}{ 2015-2016 } & \multicolumn{2}{|c|}{ Total } \\
\hline & 14,080 & & 13,803 & & 13,977 & & 41,860 & \\
\hline Male ( $n, \%$ of LC patients) & 8,830 & $62.71 \%$ & 8,351 & $60.50 \%$ & 8,314 & $59.48 \%$ & 25,495 & $60.91 \%$ \\
\hline Female ( $n, \%$ of LC patients) & 5,250 & $37.29 \%$ & 5,452 & $39.50 \%$ & 5,663 & $40.52 \%$ & 16,365 & $39.09 \%$ \\
\hline Mean age at diagnosis (y, mean $\pm \mathrm{SD}$ ) & 64.88 & \pm 10.38 & 65.28 & \pm 10.29 & 65.76 & \pm 9.87 & 65.88 & \pm 9.84 \\
\hline Male $(y$, mean \pm SD) & 64.67 & \pm 9.84 & 65.11 & \pm 9.981 & 65.69 & \pm 9.44 & 65.80 & \pm 9.41 \\
\hline Female $(y$, mean $\pm S D)$ & 65.22 & \pm 11.21 & 65.55 & \pm 10.97 & 65.86 & \pm 10.47 & 65.99 & \pm 10.45 \\
\hline \multicolumn{9}{|l|}{ Age groups } \\
\hline 20-49 & 958 & $6.80 \%$ & 890 & $6.45 \%$ & 724 & $5.18 \%$ & 2,572 & $6.14 \%$ \\
\hline $50-59$ & 4,070 & $28.91 \%$ & 3,766 & $27.28 \%$ & 3,396 & $24.30 \%$ & 11,232 & $26.83 \%$ \\
\hline $60-69$ & 4,966 & $35.27 \%$ & 4,985 & $36.12 \%$ & 5,617 & $40.19 \%$ & 15,568 & $37.19 \%$ \\
\hline $70-79$ & 2,983 & $21.19 \%$ & 3,035 & $21.99 \%$ & 3,165 & $22.64 \%$ & 9,183 & $21.94 \%$ \\
\hline 80-89 & 1,027 & $7.29 \%$ & 1,038 & $7.52 \%$ & 960 & $6.87 \%$ & 3,025 & $7.23 \%$ \\
\hline $90 \leq$ & 75 & $0.53 \%$ & 89 & $0.64 \%$ & 115 & $0.82 \%$ & 279 & $0.67 \%$ \\
\hline \multicolumn{9}{|l|}{ Morphology } \\
\hline Squamous cell carcinoma & 2,778 & $19.73 \%$ & 2,508 & $18.17 \%$ & 2,598 & $18.59 \%$ & 7,884 & $18.83 \%$ \\
\hline Adenocarcinoma & 4,152 & $29.49 \%$ & 4,073 & $29.51 \%$ & 4,128 & $29.53 \%$ & 12,353 & $29.51 \%$ \\
\hline Small cell carcinoma & 1,069 & $7.59 \%$ & 1,179 & $8.54 \%$ & 1,064 & $7.61 \%$ & 3,312 & $7.91 \%$ \\
\hline $\begin{array}{l}\text { Primary malignancy not specified } \\
\text { First line treatment }\end{array}$ & 6,081 & $43.19 \%$ & 6,043 & $43.78 \%$ & 6,187 & $44.27 \%$ & 18,311 & $43.74 \%$ \\
\hline Systemic therapy & 3,757 & $26.68 \%$ & 3,959 & $28.68 \%$ & 4,064 & $29.08 \%$ & 11,780 & $28.14 \%$ \\
\hline Surgery (including adjuvant therapy) & 2,480 & $17.61 \%$ & 1,860 & $13.48 \%$ & 1,582 & $11.32 \%$ & 5,925 & $14.15 \%$ \\
\hline
\end{tabular}

Cl, confidence interval; LC, lung cancer; SD, standard deviation. The bold values indicate Patient characteristics.

performed with $R$ version 3.5 .2 (December 20, 2018) with package boot version 1.3-20.

\section{RESULTS}

\section{Study Population}

As shown in Table 1, 41,860 newly diagnosed lung cancer cases were recorded in the Hungarian NHIF database between 2011 and 2016: 14,080 in 2011-2012, 13,803 in 2013-2014, and 13,977 in 2015-2016. 59.5-62.7\% of patients were male, the mean ages of the patients varied between 64.7 and 65.6 years during the study period. The difference between the mean age of male and female LC patients at diagnosis was not clinically relevant.

The highest numbers of patients were recorded in the 60-69 age group ( $n=15,568 ; 37.2 \%$ of total), peaking at $40.2 \%$ by the end of the study period. Patients diagnosed in the $20-49$ age group represented $6.1 \%$ of the total LC population. The histological type of the tumor was recorded in more than $50 \%$ $(56.3 \%)$ of the cases. The majority of lung cancers was nonsquamous cell carcinoma (adenocarcinoma, 29.5\%). 7.9\% of the total lung cancer population had small-cell carcinoma.

\section{Long-Term Survival Short and Long-Term Survival}

$42.2 \%$ of the total lung cancer population $(n=41,860)$ survived the first year. The overall survival rate by the end of the second year the survival rate was $29.3 \%$, and the 5-year survival rate was $17.9 \%$ (Figure 1). Female lung cancer patients had better survival throughout the study period. Female patients had a $47.6 \%$ oneyear survival rate vs. $38.8 \%$ for males. 5-year survival rates for females and males were 22.8 and $14.8 \%$, respectively (Figure 1).
Females had $22.88 \%$ better lung cancer survival compare to males (HR: 0.77; 95\% CI: 0.75-0.79, $p<0.001$ ) (Figure 2). The difference in survival between females and males increased in the younger age groups reaching $37.16 \%$ in the youngest cohort. While these differences decreased to $21 \%$ and $17 \%$ in the $60-69$ and 70-79 age groups. The survival differences between the genders were found to be non-significant above the age of 80 (Figure 2).

One-year survival rates were highest in the 20-49 age group, reaching $55.1 \%$, while the largest $50-59$ and $60-69$ age cohorts had 48.3 and $44.1 \%$ survival rates by the end of the first follow-up year. The long-term survival rates decreased to $31.3,22.5,17.7$, $10.2 \%$ in the $20-49,50-59,60-69$ and $70-79$ age cohorts, respectively (Supplementary Figure S1).

Lung cancer patients diagnosed between 2015 and 2016 had a $5.3 \%$ lower risk of mortality compared to patients in the 2011-2012 study period (HR 0.95 95\% CI 0.92-0.97; $p=$ 0.001 ) adjusted only for age (Figure 3 ). When we adjusted the change of survivals by age, sex, histology type of lung cancer and main treatment type, we got $9.2 \%$ improvement $(\mathrm{HR}=0.91 ; 95 \%$ CI: $0.88-0.93 ; p<0.001)$.

The improvement of survival was higher by younger age, where $p$ for trend analysis was significant, interaction $p=0.014$. We also calculated this interaction between age above or below 60 years: interaction: $p=0.024$ interaction (period and type): $p=0.003$ (These results were adjusted for sex, histology type of lung cancer and treatment types).

Improvement of survival was found to be higher at females (HR:0.89; 95\%CI:0.85-0.93; $p<0.001$ ) than males (HR: 0.93; 95\%CI:0.90-0.96; $p<0.001)$, especially at younger age, thought the interaction analysis for sex was not significant $(p=0.1024)$ (These results were adjusted for age (expect 


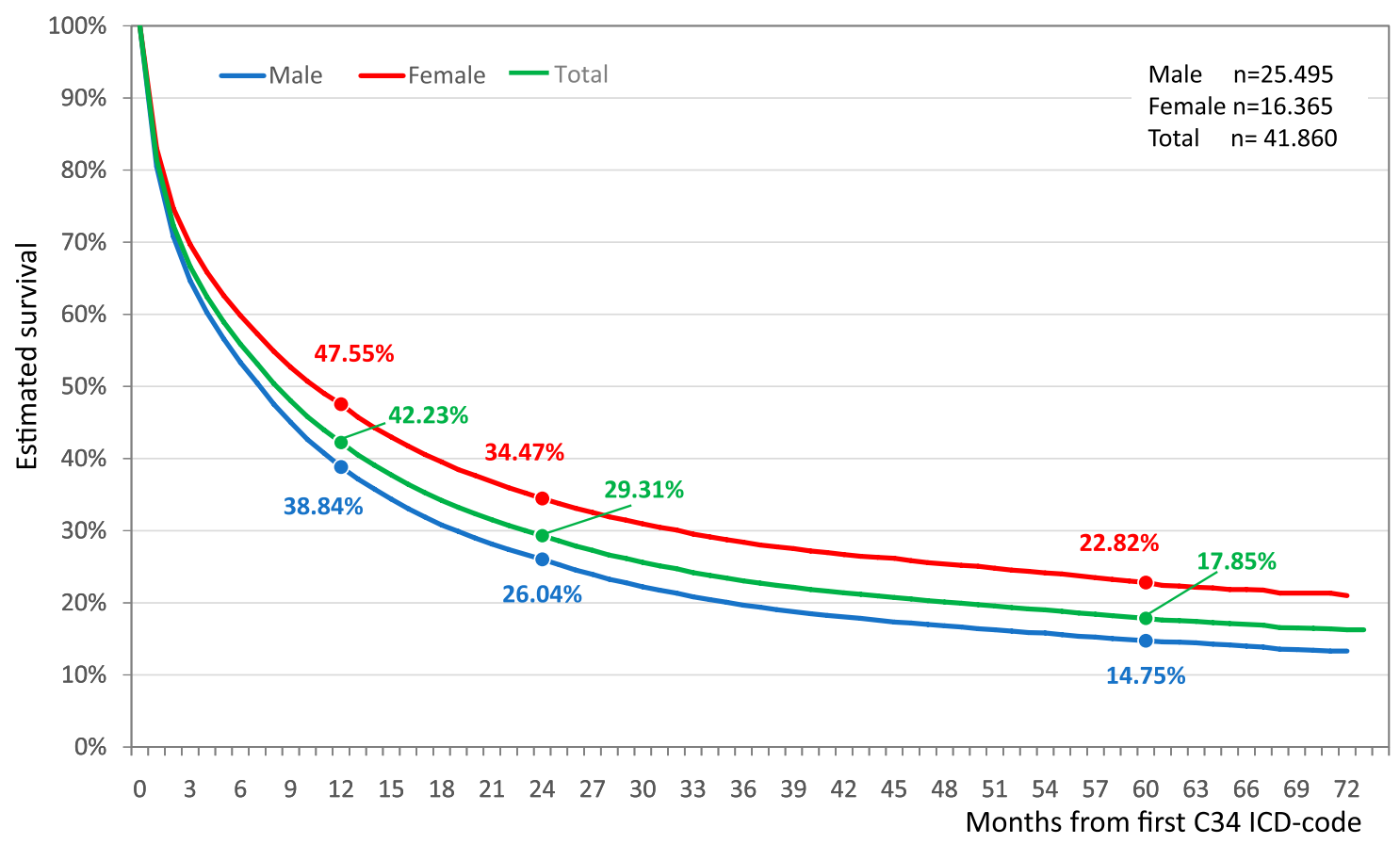

FIGURE 1 | Estimated overall survival of Hungarian lung cancer patients diagnosed between 2011 and 2016.

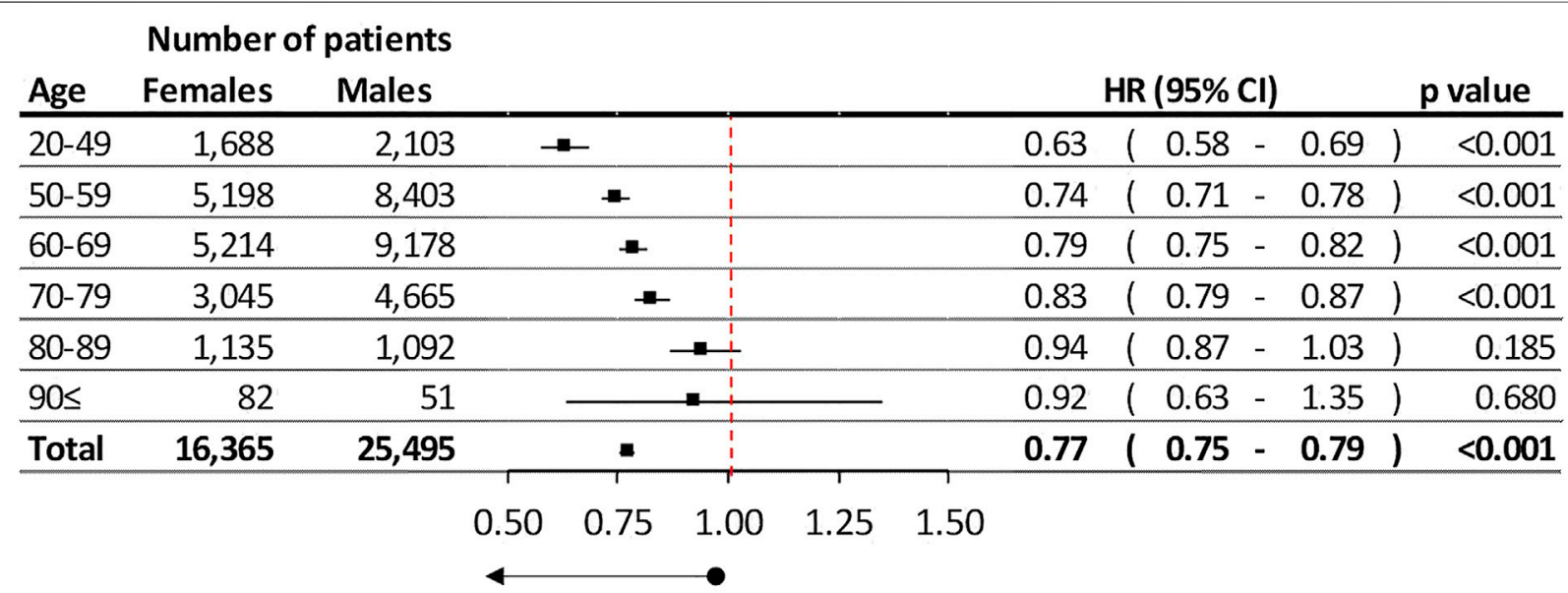

Risk is lower in females

FIGURE 2 | Difference of estimated overall lung cancer survival between female and male in different age groups.

detailed age perspective) histology type of lung cancer and treatment types).

When we compared the 2015-16 and 2011-2012 period by histology type of lung cancer, we found the highest improvement at adenocarcinoma, where hazard ratio was 0.89 (95\%CI: $0.85-0.93 ; p<0.001)$, especially under age of 60 years, where HR was 0.86 (95\%CI:0.79-0.93; $p<0.001)$. On the other hand, we recorded 5\%, but not significant improvement at patients having squamous cell carcinoma (HR:0.95; 95\%CI:0.89-1.00; $p=0.065$ ), while there were no change found at small-cell carcinoma (HR: 1.02; 95\%CI: $0.94-1.12 ; p=0.594)$. Interaction analysis showed significant relation for type of histology $(p=0.003)$ (These results were adjusted for sex, age (expect age related parts) of lung cancer patients and treatment types).

We also analyzed those lung cancer patients having systemic treatment in late stage or surgery in early stage. At those, whom had surgery in first line treatment, improvement were not detected (HR:1.00; 95\%CI: 0.91-1.11; $p=0.976$ ), while we 


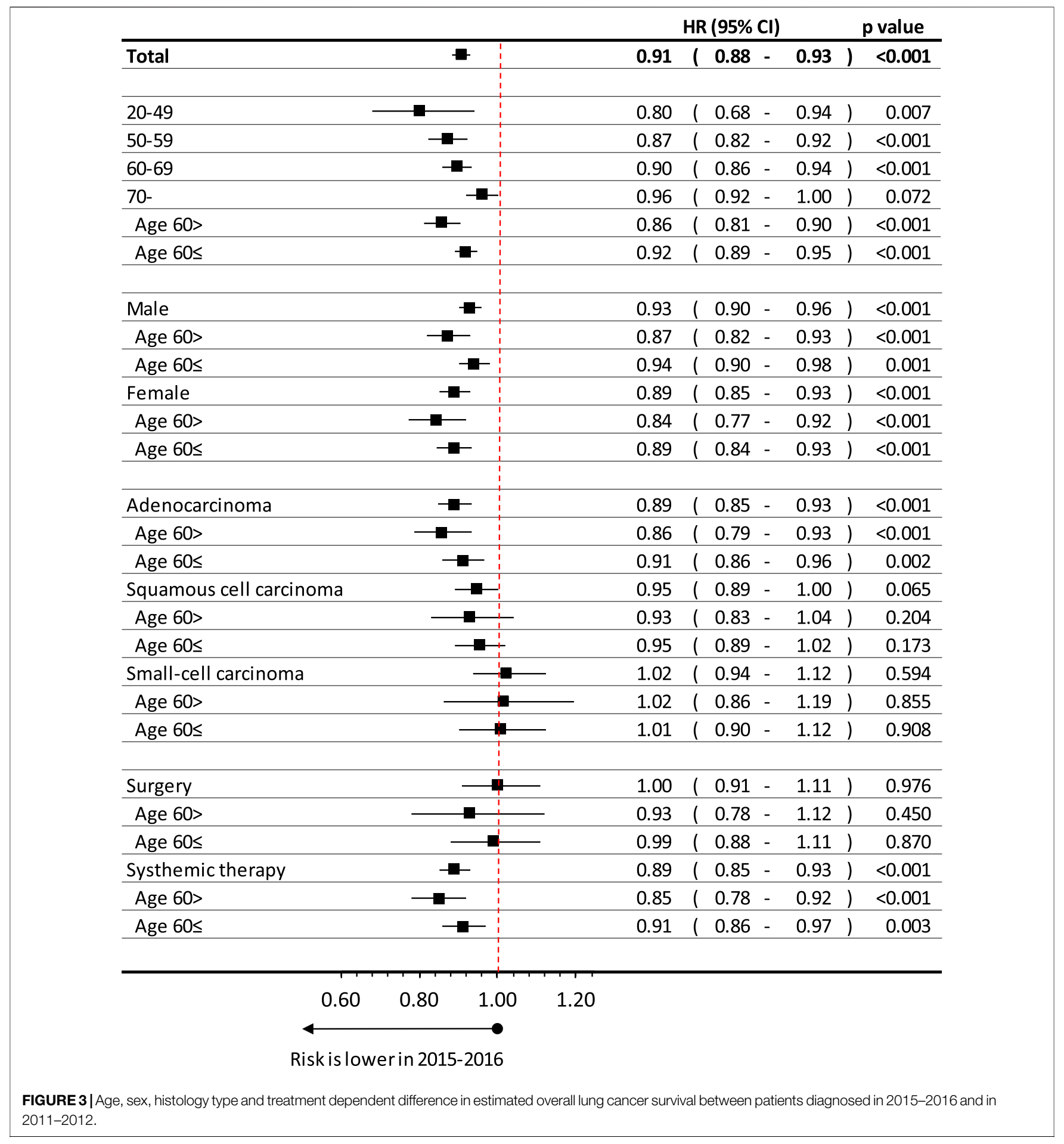

recorded relevant increase in survival at patients received systemic therapy (HR:0.89; 95\%CI:0.85-0.93; $p<0.001$ ), especially those, were age below 60 years (HR:0.85; 95\%CI: 0.78-0.92); $p<0.001)$.

Based on the morphological report of the NHIF, the histological type of lung cancer was recorded in $56.3 \%$ of all LC patients. Adenocarcinoma was more common in females, with $33.4 \%$ vs.
$27.0 \%$ in male patients, while squamous-cell carcinoma was more frequently found in the male patient population, $22.7 \%$ in males vs. $12.9 \%$ in females (Supplementary Table S1). The best crude survival rates among LC patients could be found in patients with adenocarcinoma ( $n=12,353$ ), where the 1 - and 5-year survival rates were 53.7 and $20.5 \%$, respectively (Figure 4). The poorest survival rates were recorded in the small-cell lung 


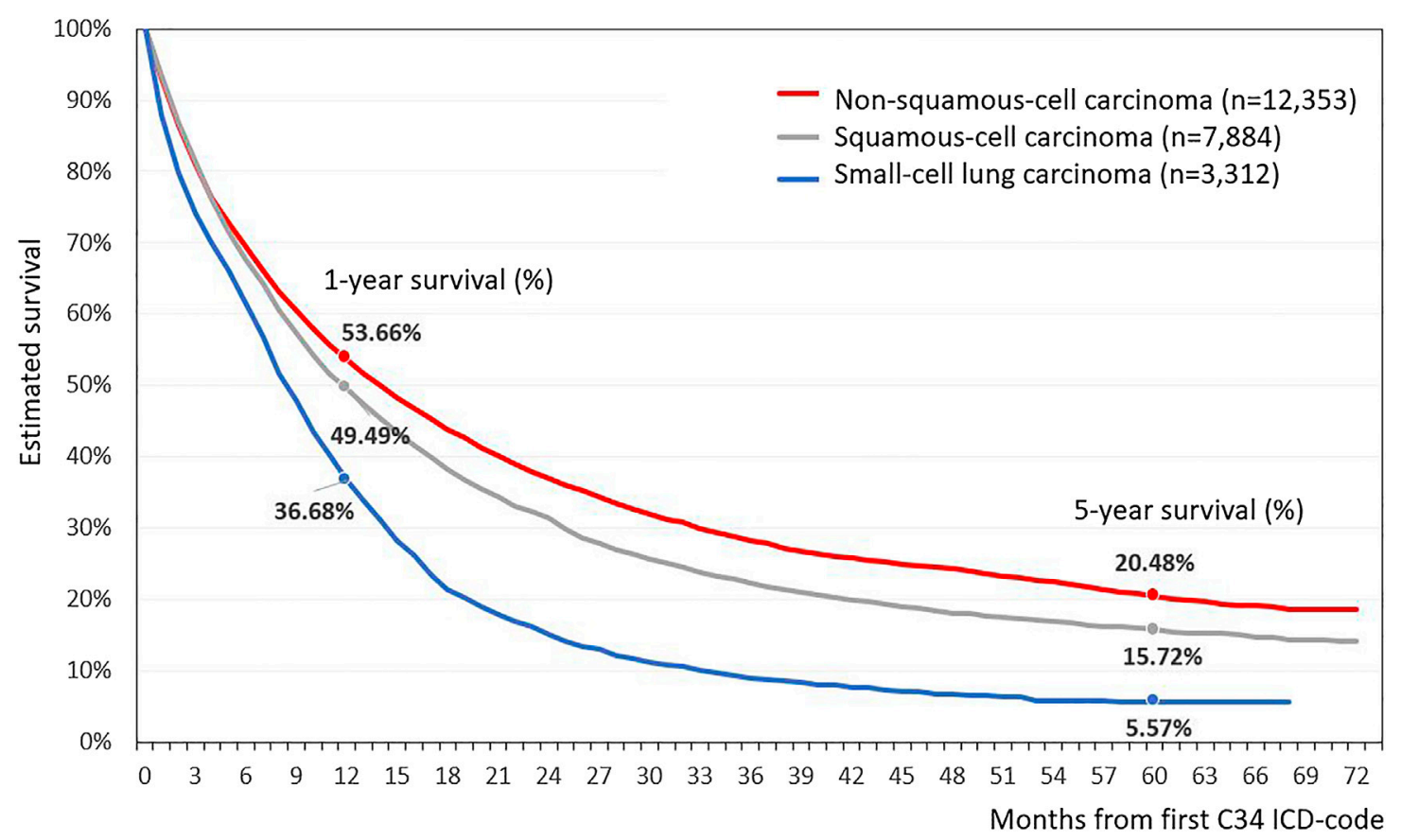

FIGURE 4 | Estimated survival of Hungarian lung cancer patients depending on histological characteristics.

carcinoma group $(n=3,312)$ where the 5 -year survival proved to be only $5.6 \%$.

We could record the $1^{\text {st }}$ line treatment as systemic therapy at $28.14 \%$ of all patients (including chemo and targeted therapy), and surgery (including those having adjuvant treatment) at $14.15 \%$. The share of systemic therapy increased from 26.68 onto $29.08 \%$, while share of those having surgery in early stage, decreased from 17.60 onto $11.32 \%$.

\section{DISCUSSION}

Our retrospective, longitudinal analysis provides long-term LC overall survival data from Hungary based on a comprehensive, nationwide data source. This study is also the first to report an improvement in LC survival during the 2011-2016 period in Hungary. The main findings of this large-scale evaluation can be summarized as follows:

1. Hungarian LC patients had a 5-year overall survival rate of $17.9 \%$ between 2011 and 2016, with a 5.3\% improvement in survival during the 6 year-study period.

2. The survival of LC depends on age and sex, as well as on cancer type. Females had a $23 \%$ lower mortality risk than male LC patients, and the highest crude survival rates were found in patients with adenocarcinoma.

\section{Short-Term Survival of Lung Cancer}

Despite several recently published analyses on lung cancer in Europe [10-13], neither short-term (1-year) nor long-term (5Y) data have been available regarding survival in Hungarian patients. When we compared our short-term survival results with findings from the Danish Lung Cancer Group study [14], one-year survival rates were comparable $(42.37 \%$ vs. $43 \%$ for the Hungarian 2011-2012 and Danish 2010-2012 interval, respectively), although the Danish study used a different diagnostic period. Additionally, the drop of the survival curve of Hungarian LC patients was more rapid and occurred earlier. The distribution of male and female 1-year survival rates was also similar, 39.2\% vs. 39\% in Hungarian and Danish males, and $47.66 \%$ vs. $47 \%$ in Hungarian and Danish females, respectively. The short-term survival rates in our study were unequivocally higher than the EUROCARE-5 study reported in Eastern European countries (32.4\%) [15]. They corresponded with the Central European country results (42.3\%), although this study analyzed patients diagnosed between 2000 and 2007 [15]. The Cancer Research United Kingdom database provided short-term LC survival data for both genders in the 2010-2011 diagnostic period [16], where net survival rates were $30.4 \%$ in males and $35.1 \%$ in females, nevertheless, LC survival rates in the United Kingdom tended to be at the lower end of rates collected in Western European countries [7-15].

\section{Long-Term Survival of Lung Cancer}

Studies involving patients diagnosed with lung cancer before 2014 were the only data source which could provide 5-year survival data in 2019. Hence, a number of international publications and data sources were of limited comparability with regard to our study encompassing the 6 year period of 2010-2016. In the CONCORD-3 study, the age-standardized 5-year survival rates varied between 7.7 and $15.7 \%$ for East-Central Europe in the 
2010-2014 diagnostic period [7]. In our study, we observed a $17.9 \%$ 5-year survival rate in the 2010-2011 diagnostic period. Since our defined age cohorts were slightly different than what the CONCORD-3 study used for standardization, we were not able to directly compare our national results with other East-Central European countries. Nevertheless, with a similar age distribution in our study population as well as in neighboring countries, Hungarian survival rates could be considered comparable with the survival rates of countries in the region and in most Western European countries. These similar numbers could be due to the same, limited LC treatment options of the early 2010s as well as the advanced stage of LC at diagnosis. Gender-specific survival data for comparison were only available from the Cancer Research United Kingdom database [16] where the 5-year net survival rates were 8.4 and $11.6 \%$ in males and females, respectively. These results were lower compared to our findings ( 14.75 and $22.84 \%$ in males and in females), although the gender differences tended to be similar between the two analyses.

\section{Trends in Long Term Survival}

We demonstrated a $5.3 \%$ improvement in survival $(9.0 \%$ adjusted) between 2015-2016 and 2010-2011 periods, which was an increase expressed by hazard ratio, hence not the change of the fifth year survival rates as 2015-2016 period did not have such a long follow-up period. Nevertheless, the change is close to a yearly $1 \%$ improvement. If we compare the trends of lung cancer survival in other study, we can find a $18.9 \%$ vs $12.4 \%$ in Denmark, $14.7 \%$ vs $10.0 \%$ in United Kingdom, $20.4 \%$ vs $15.4 \%$ in Norway and $21.7 \%$ vs $18.5 \%$ in Canada by comparing the 2010-2014 and 2005-2009 periods based on the ICBP SURVMARK-2 study [17]. In this aspect, this is a $3-6 \%$ absolute change of fifth year net survival within a 10-year period, which is hardly comparable with the trend of our survival improvement in a 6-year period, though these changes are in the same range. The US SEER database presented the fifth year survival change from 18.42 onto $21.41 \%$ from 2007 to 2012 , in a same, 6-year period, which is an average $2.1 \%$ yearly improvement [18]. If we investigate the trends of fifth year lung cancer survival in the CONCORD-3 study, we can see a $0.8 \%$ absolute change in Czech, $0.7 \%$ in Slovakia and $0.3 \%$ in Poland between 2010-2014 and 2005-2009 period, which is a $8.16,6.67$, and $2.13 \%$ relative change consequently where the Slovak and Czech results are comparable with our improvement [7]. Nevertheless, in the Western EU countries (like Denmark, Norway, United Kingdom, Ireland), CONCORD-3 study presented even a $25-35 \%$ relative improvement in the relative change of $5^{\text {th }}$ year survival during this period. All in all, we can conclude that the size of lung cancer survival improvement is within the range of previously presented study results, even if the data are hardly comparable. Besides, if we expect the at least the same improvement rate of the Hungarian lung cancer survival in last years, the $5^{\text {th }}$ year survival may exceed the $20 \%$ by the end of this decade, especially due to the impact of newly approved immunotherapies.

\section{Gender Differences in Lung Cancer Survival}

We found $23 \%$ better survival rates for female LC patients than for males, and survival differences tended to be larger (up to 37\%) in the younger age groups. Gender differences have been investigated in several studies during the past decades, like in the analysis from the US lung cancer database [8]. Average survival rates were $13.0 \%$ in males and $17.7 \%$ in females. The ECOG 1594 trial involving 1,157 patients found a statistically significant, 1.9-month improvement in median survival among women compared to men, despite similar response rates and greater toxicity from treatment and no differences regarding other known prognostic factors [19]. Population-based studies have supported this finding, including a multivariate analysis of more than 20,000 lung cancer cases from Poland that found a 1.15 relative risk (RR) of death in men [20]. An evaluation of 4,618 NSCLC patients who were prospectively enrolled and followed from 1997 to 2002 at the Mayo Clinic in Rochester, Minnesota found a 1.20 relative risk of mortality in men after adjusting for age, histology, cancer stage, smoking history, and treatment [21]. These differences in survival between genders may be multifactorial [22]. Due to gender differences in smoking habits, females were prone to develop adenocarcinoma more frequently [ [23-25]] which LC lung type results in better survival rates than other histological types of LC [ [26, 27]]. Our analysis confirmed that adenocarcinoma was more frequently diagnosed in females than in men. Additionally, females tended to have higher rates of surgical treatment in the early stages of lung cancer [28], which resulted in improved survival outcomes in these stages compared to other modalities of treatment [29].

On the other hand, though the improvement in survival was higher at females, especially at younger age, the interaction analysis was not significant for sex, therefore we could conclude that sex did not play role in the time dependent improvement of lung cancer.

\section{Age-Dependent Survival of Lung Cancer}

Older lung cancer patients had poorer survival than younger patients [8]. All age groups have shown significant improvements in survival rates since the 1970s, and the greatest improvements were recorded in the youngest age groups (15-44 years), as reported by Lu et al. [10]. Our findings have confirmed these trends, since the youngest lung cancer patients had $31.3 \%$ crude 5-years survival rate, compared to $10.2 \%$ in the age group of $70-79$ years. We found more pronounced improvements in age-dependent survival rates at younger cohorts during the 2015-2016 interval than in the 2011-2012 diagnostic period. Though we could not identify the prevalence of typical carcinoids at young cohort, it may also play role in better survival results of this cohort due to its good prognosis and curability [30].

\section{Long-Term Survival of Lung Cancer by Cancer Type}

Lung cancer survival is known to vary depending on the histological type of the cancer. Patients with adenocarcinoma have been shown to have higher survival rates compared to those with squamous cell carcinoma, while patients with small-cell carcinoma have been found to have the lowest 5-year survival rates compared to the previous two LC subtypes $[10,31]$. In our study, the histological 
types of lung cancer could be identified in $56.3 \%$ of the cases. 5-year survival rates among patients with adenocarcinoma and those with squamous cell carcinoma were 20.5 and $15.7 \%$, respectively, and were comparable with international findings [10]. In line with previous observations, adenocarcinoma occurred more frequently while squamous cell carcinoma less frequently in females.

We found the highest improvement of survival in case of adenocarcinoma (11\%), especially those, having age below 60 years at time of diagnosis. On the other hand, we did not find any change in case of small cell carcinoma, while relevant, 5\%, but not significant at squamous cell carcinoma. This result is parallel with the historic changes in the treatment of different types of lung cancer. The aera of personalized treatment, the introduction of targeted therapy was most frequent at adenocarcinoma, especially at young patients (ALK inhibitors), while in older women, the possibility of EGFR inhibition resulted in visible improvement [32]. On the other hand, we did not have any significant change in treatment options patients with small cell carcinoma between 2011 and 2016. Nevertheless, these types of changes reflected in a $11 \%$ overall change in survival of patient population received systemic therapy, while we could not find relevant improvement at those, having surgery in first line treatment.

Strength of our study is the large number of diagnosed lung cancer patients, the carefully cleaned data, the 6-year-long follow-up period and the nationwide nature of the NHIF database, which all provide a solid foundation for drawing conclusions from our analysis. However, our study is not free from limitations. The applied exclusion criteria may have led to the exclusion of patients who had other cancer types besides lung cancer. According to our estimations however, this patient population is negligible. Moreover, the NHIF database contained data on the pathomorphology of lung cancer in only $52 \%$ of the cases. Staging, ECOG status and laboratory tests of patients were not recorded in the NHIF database. Consequently, we were not able to provide specific survival data based on these characteristics. Other limitation of our study is that we were able to provide only overall survival of lung cancer patients, and we did not estimate net survival, hence, we could not adjust the age related survival analysis to the natural survival rates of the general population. Nevertheless, as lung cancer patients have much higher mortality than the reference general population, and the vast majority of their mortality is caused by the cancer itself, this does not have a severe effect on the results and interpretation. Beside, we were able to detect the type of first treatment only certain part of lung cancer population. Those, having first line treatment as part of a study or received radiotherapy or palliative care, were not recorded in the NHIF database, hence we evaluated those, whom $1^{\text {st }}$ line treatment was unambiguous, like systemic therapy or surgery and only from the perspective of survival improvement analysis.

\section{CONCLUSION}

To summarize, our study is the first to provide long-term survival data on Hungarian lung cancer patients and to report a 9.2\% adjusted improvement in survival during the 6-year study period. The 5-year crude survival rate of $17.8 \%$ is comparable with neighboring countries' data from the same period. Female lung cancer patients had a $23 \%$ better survival rate than males, which could be attributed to a higher incidence rate of adenocarcinoma in women. Survival rates were comparable to-and at the higher end of-rates registered in other East-Central European countries.

\section{DATA AVAILABILITY STATEMENT}

The raw data supporting the conclusions of this article will be made available by the authors, without undue reservation.

\section{ETHICS STATEMENT}

The study was approved by the National Ethical Committee, with the 10338-5/2019/EKU ethical approval number and the I043/88/ 2019 study license number.

\section{AUTHOR CONTRIBUTIONS}

$\mathrm{KB}$ and $\mathrm{ZK}$ equally contributed to this work.

\section{FUNDING}

MSD Pharma Hungary sponsored the data and statistical analysis as well as medical writer review for manuscript and will secure the publication fee if manuscript will be published. The authors declare that this study received funding from MSD Pharma Hungary Ltd. The funder had the following involvement with the study:in the study design, collection, analysis, interpretation of data, the writing of this article but was not involved in the decision to submit it for publication. JM was supported by the Hungarian Brain research Program (grant 2017-1.2.1NKP-2017-00002), and the Hungarian NRDI Office (grant K-129065).

\section{CONFLICTS OF INTEREST}

ZK, AV, ZN-E, and AD are employees of MSD Pharma Hungary Ltd. $\mathrm{KH}$ is a research fellow at Eötvös Loránd University. BN and ZV are employees of Eötvös Loránd University where their contribution to this project was financially compensated. $\mathrm{KB}$ and $\mathrm{GO}$ are employees of National Korányi Institute of Pulmonology and have received speaker honorarium from MSD Hungary. GG is employee of Oncology Center of Törökbálint and has received speaker honorarium from MSD Hungary. LT and VM are employees of Semmelweis University. LU is employee of Mátra Gyógyintézet. NB is employee of University of Debrecen. VS is employee of University of Pécs. GR and ZA-T are employees of RxTarget Ltd. where their contribution to this project was financially compensated. ZB is employee of Syntesia Ltd. and her contribution to this project was financially compensated.

The remaining authors declare that the research was conducted in the absence of any commercial or financial relationships that could be construed as a potential conflict of interest. 


\section{ACKNOWLEDGMENTS}

We would like to thank the NHIF for providing a comprehensive dataset for our analysis, and ZB of Syntesia Medical Communications for medical writing support.

\section{REFERENCES}

1. Ding L, Getz G, Wheeler DA, Mardis ER, McLellan MD, Cibulskis K, et al. Somatic mutations affect key pathways in lung adenocarcinoma. Nature (2008). 455:1069-75. doi:10.1038/nature 07423

2. Ferlay J, Colombet M, Soerjomataram I, Dyba T, Randi G, Bettio M, et al. Cancer incidence and mortality patterns in Europe: estimates for 40 countries and 25 major cancers in 2018. Eur J Cancer (2018). 103:356-87. doi:10.1016/j.ejca.2018.07.005

3. Hakulinen T, Engholm G, Gislum M, Storm HH, Klint Å, Tryggvadóttir L, et al. Trends in the survival of patients diagnosed with cancers in the respiratory system in the Nordic countries 1964-2003 followed up to the end of 2006. Acta Oncologica (2010). 49(5):608-23. doi:10.3109/02841860903575281

4. Torre LA, Siegel RL, Jemal A Lung cancer statistics. Adv Exp Med Biol (2016). 893:1-19. doi:10.1007/978-3-319-24223-1_1

5. Jemal A, Siegel R, Xu J, Ward E Cancer statistics, 2010. CA Cancer J Clin (2010). 60(5):277-300. doi:10.3322/caac.20073

6. Heuvers ME, Hegmans JP, Stricker BH, Aerts JG Improving lung cancer survival; time to move on. BMC Pulm Med (2012). 12:77. doi:10.1186/1471-2466-12-77

7. Allemani C, Matsuda T, Di Carlo V, Harewood R, Matz M, Nikšić M, et al. Global surveillance of trends in cancer survival 2000-14 (CONCORD-3): analysis of individual records for 37513025 patients diagnosed with one of 18 cancers from 322 population-based registries in 71 countries. Lancet (2018). 391(10125):1023-75. doi:10.1016/S0140-6736(17)33326-3

8. American Cancer Society. Cancer facts \& figures 2018. Atlanta: American Cancer Society (2018).

9. Woodard GA, Jones KD, Jablons DM Lung cancer staging and prognosis. Cancer Treat Res (2016). 170:47-75. doi:10.1007/978-3-319-40389-2_3

10. Lu T, Yang X, Huang Y, Zhao M, Li M, Ma K, et al. Trends in the incidence, treatment, and survival of patients with lung cancer in the last four decades. Cmar (2019). 11:943-53. doi:10.2147/cmar.s187317

11. Bogos K, Kiss Z, Gálffy G, Tamási L, Ostoros G, Müller V, et al. Revising incidence and mortality of lung cancer in central Europe: an epidemiology review from Hungary. Front Oncol (2019). 9:1051. doi:10.3389/fonc.2019.01051

12. Tan KS, Eguchi T, Adusumilli PS Reporting net survival in populations: a sensitivity analysis in lung cancer demonstrates the differential implications of reporting relative survival and cause-specific survival. Clep (2019). 11:781-92. eCollection 2019. doi:10.2147/CLEP.S210894

13. Arnold M, Rutherford MJ, Bardot A, Ferlay J, Andersson TM, Myklebust TA, et al. Progress in cancer survival, mortality, and incidence in seven high-income countries 1995-2014 (ICBP SURVMARK-2): a population-based study. Lancet Oncol (2019). 20(11):1493-505. doi:10.1016/S1470-2045(19)30456-5

14. Jakobsen E, Rasmussen TR, Green A Mortality and survival of lung cancer in Denmark: results from the Danish lung cancer group 2000-2012. Acta Oncologica (2016). 55(Suppl. 2):2-9. doi:10.3109/0284186x.2016.1150608

15. Rossi S, Baili P, Capocaccia R, Caldora M, Carrani E, Minicozzi P, et al. The EUROCARE-5 study on cancer survival in Europe 1999-2007: database, quality checks and statistical analysis methods. Eur J Cancer (2015). 51(15): 2104-19. doi:10.1016/j.ejca.2015.08.001

16. Cancer Research UK (2019). https://www.cancerresearchuk.org/healthprofessional/cancer-statistics/statistics-by-cancer-type/lung-cancer/survival\#headingZero (Accessed January 24, 2020).

17. Arnold M, Rutherford MJ, Bardot A, Ferlay J, Andersson TM-L, Myklebust TÅ, et al. Progress in cancer survival, mortality, and incidence in seven high-income countries 1995-2014 (ICBP SURVMARK-2): a population-based study. Lancet Oncol (2019). 20(11):1493-505. doi:10.1016/s1470-2045(19)30456-5

18. National Cancer Institute. Surveillance, epidemiology and end result program. Bethesda: (SEER database): cancer stat facts: lung and bronchus cancer (2020).

\section{SUPPLEMENTARY MATERIAL}

The Supplementary Material for this article can be found online at: https://www.por-journal.com/articles/10.3389/pore.2021.603937/ full\#supplementary-material.

https://seer.cancer.gov/statfacts/html/lungb.html. Last update (Accessed October 31, 2020).

19. Wakelee HA, Wang W, Schiller JH, Langer CJ, Sandler AB, Belani CP, et al. Survival differences by sex for patients with advanced non-small cell lung cancer on eastern cooperative oncology group trial 1594. J Thorac Oncol (2006). 1(5):441-6. doi:10.1016/s1556-0864(15)31609-9

20. Radzikowska E, Głaz P, Roszkowski K Lung cancer in women: age, smoking, histology, performance status, stage, initial treatment and survival. Populationbased study of 20561 cases. Ann Oncol (2002). 13:1087-93. doi:10.1093/ annonc/mdf187

21. Visbal AL, Williams BA, Nichols FC, Marks RS, Jett JR, Aubry M-C, et al. Gender differences in non-small-cell lung cancer survival: an analysis of 4,618 patients diagnosed between 1997 and 2002. Ann Thorac Surg (2004). 78: 209-15. doi:10.1016/j.athoracsur.2003.11.021

22. Rivera M Lung cancer in women: differences in epidemiology, biology, histology, and treatment outcomes. Semin Respir Crit Care Med (2013). 34(6):792-801. doi:10.1055/s-0033-1358550

23. Devesa SS, Bray F, Vizcaino AP, Parkin DM International lung cancer trends by histologic type: male:female differences diminishing and adenocarcinoma rates rising. Int J Cancer (2005). 117(2):294-9. doi:10.1002/ijc.21183

24. Meza R, Meernik C, Jeon J, Cote ML Lung cancer incidence trends by gender, race and histology in the United States, 1973-2010. PLoS One (2015). 10(3): e0121323. doi:10.1371/journal.pone.0121323

25. Welcker K Genderspezifische Unterschiede des Lungenkarzinoms. Zentralbl Chir (2015). 140(3):260-5. doi:10.1055/s-0034-1396231

26. Ramalingam S, Dinan MA, Crawford J Survival comparison in patients with stage IV lung cancer in academic versus community centers in the United States. J Thorac Oncol (2018). 13(12):1842-50. doi:10.1016/j.jtho.2018.09.007

27. Kinoshita FL, Ito Y, Morishima T, Miyashiro I, Nakayama T Sex differences in lung cancer survival: long-term trends using population-based cancer registry data in Osaka, Japan. Jpn J Clin Oncol (2017). 47(9):863-9. doi:10.1093/jjco/ hyx094

28. Fu JB, Kau TY, Severson RK, Kalemkerian GP Lung cancer in women. Chest (2005). 127(3):768-77. doi:10.1378/chest.127.3.768

29. Cerfolio RJ, Bryant AS, Scott E, Sharma M, Robert F, Spencer SA, et al. Women with pathologic stage I, II, and III non-small cell lung cancer have better survival than men. Chest (2006). 130(6):1796-802. doi:10.1378/chest. 130.6.1796

30. Velinovic M, Jankovic R, Jovanovic D, Skodric Trifunovic V, Gavrilovic D, Stojsic J, et al. Tumor characteristics, expressions of ERCC1, Bax, p53, IGF1R, $\mathrm{Bcl} 2, \mathrm{Bcl} 2 / \mathrm{Bax}$ and prognostic factors for overall survival in patients with lung carcinoid. J BUON (2019). 24(1):256-66.

31. Walters S, Maringe C, Coleman MP, Peake MD, Butler J, Young N, et al. Lung cancer survival and stage at diagnosis in Australia, Canada, Denmark, Norway, Sweden and the UK: a population-based study, 2004-2007. Thorax (2013). 68(6):551-64. doi:10.1136/thoraxjnl-2012-202297

32. Duma NN, Santana-Davila JR, Molina JR Non-small cell lung cancer: epidemiology, screening, diagnosis, and treatment. Mayo Clinic Proc (2019). 94(8):1623-40. doi:10.1016/j.mayocp.2019.01.013

Copyright (๔) 2021 Bogos, Kiss, Tamási, Ostoros, Müller, Urbán, Bittner, Sárosi, Vastag, Polányi, Nagy-Erdei, Daniel, Vokó, Nagy, Horváth, Rokszin, Abonyi-Tóth, Barcza, Gálffy and Moldvay. This is an open-access article distributed under the terms of the Creative Commons Attribution License (CC BY). The use, distribution or reproduction in other forums is permitted, provided the original author(s) and the copyright owner(s) are credited and that the original publication in this journal is cited, in accordance with accepted academic practice. No use, distribution or reproduction is permitted which does not comply with these terms. 